\title{
Styrene polymerization with a super ionically-tagged iron catalyst
}

\author{
Thyago S. Rodrigues ${ }^{\mathrm{a} a}$ (IC), Gisele A. Medeiros ${ }^{\mathrm{a}}$ (IC), Priscila M. Lallib $(\mathrm{PG})$, Marcos \\ N. Eberlin ${ }^{\mathrm{b}}(\mathrm{PQ})$, Fabrício M. Silva ${ }^{\mathrm{a}}(\mathrm{PQ})$, Brenno A. D. Neto ${ }^{\mathrm{a}}(\mathrm{PQ})$ \\ ${ }^{a}$ Laboratory of Medicinal and Technolical Chemistry - University of Brasilia, Chemistry Institute (IQ-UnB). \\ ${ }^{b}$ Thomson Mass Spectrometry Laboratory - States University of Campinas. \\ *thyagosrodrigues@hotmail.com
}

Keywords: Ionic liquids, styrene, polymerization.

\section{INTRODUCTION}

lonic liquids (ILs) are defined as liquid electrolytes composed entirely of ions. More recently, the melting point criterion has been proposed to distinguish between molten salt and ionic liquids. ${ }^{1}$ IL can be used as excellent alternative to organic solvents and catalysis. ILs such as $\mathrm{BMI} \mathrm{Fe}_{\mathrm{x}} \mathrm{Cl}_{3 \mathrm{x}+1}$ $(X=1,2)$ with iron atoms acting as Lewis acids in the anionic moiety were tested as catalysts for styrene polymerization $^{2}$ with impressive results. Iron is considered an attractive metal due to ecological, abundance and cost reasons. Herein, we describe the use of an ionically-tagged catalyst for the styrene polymerization.

\section{RESULTS AND DISCUSSION}

Commonly, the observed molar ratio to promote the polymerization reaction is 10:1 (monomer:catalyst). Moreover, additives such as benzoyl peroxide, aryl or akyl chlorides are also used as initiators.

Firstly, $\mathrm{BMI} . \mathrm{FeCl}_{4}$ was tested as the catalyst. Nevertheless, it was required the addition of an initiator (benzoyl peroxide). Fortunately, $\mathrm{BMI} \mathrm{Fe}_{2} \mathrm{Cl}_{7}$ proved to be an efficient catalyst for the styrene polymerization without any initiator with great activity (Table 1). Catalyst activity is sustained even at very low concentrations (Table 1, Entry 2).

Table 1. The catalyst $\left(\mathrm{BMI}_{\mathrm{Fe}} \mathrm{Fe}_{2} \mathrm{Cl}_{7}\right)$ yield dependence.

\begin{tabular}{cccc}
\hline Entry $^{\text {a }}$ & $\begin{array}{c}\text { Molar Ratio } \\
\text { (monomer:catalyst) }\end{array}$ & $\begin{array}{c}\text { Time } \\
(\text { mim) }\end{array}$ & $\begin{array}{c}\text { Yield } \\
(\%)\end{array}$ \\
\hline 1 & $1000: 1$ & 15 & 71 \\
2 & $10000: 1$ & 120 & 40
\end{tabular}

${ }^{a}$ reaction performed at $70^{\circ} \mathrm{C}, 5 \mathrm{~mL}(43 \mathrm{mmol})$ of styrene under inert atmosphere.

An important feature is the fact that ILs do play a role. In Figure 1 is possible to observe that the reaction carried out in the presence of an IL is far better than the reaction conducted in the absence of any IL.

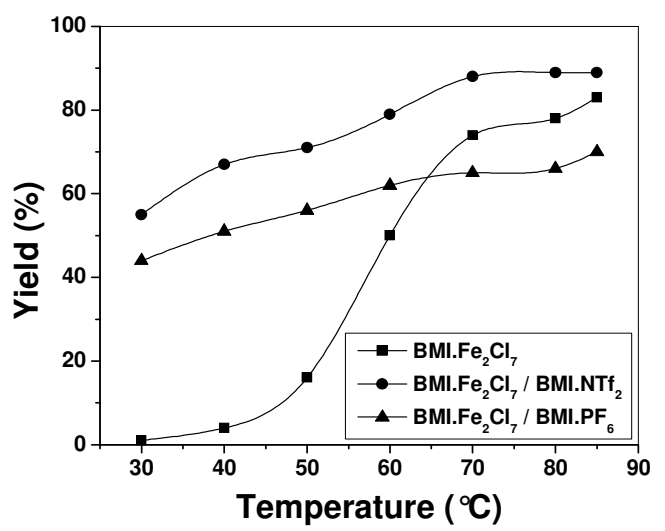

Figure 1. Comparative yield using $\mathrm{BMI} . \mathrm{Fe}_{2} \mathrm{Cl}_{7}$ with catalyst supported in IL (BMI.NTf 2 and BMI.PF B $_{6}$.

It is believed that the reaction is proceeding through a cationic mechanism. In this sense, it is more than reasonable to expect that the presence of ILs is stabilizing the charged intermediates through ion-pairing formation. As a consequence, yields and reaction time can be optimized. Moreover, the presence of an imidazolium cation in the catalyst structure allows a better immobilisation and reusability.

\section{CONCLUSION}

The catalyst $\mathrm{BMI} . \mathrm{Fe}_{2} \mathrm{Cl}_{7}$ can be used for the cationic styrene polymerization at $70 \stackrel{\circ}{ } \mathrm{C}$ with high yields. The catalyst requires no addition of any initiator. When used different IL as the reaction media, better yields are observed.

\section{ACKNOWLEDGEMENTS}

FAPDF, CAPES, FINATEC e CNPq for the financial support.

\section{REFERENCES}

Dupont, J. Souza, R. F. and Suarez, P. A. Z. Chem. Rev. 2002, 102,

3667.
${ }^{2}$ Kubisa, P. J. Polym. Sci. part A: polym. chem. 2005, 43, 4675- 4683. 